Annales Geophysicae (2002) 20: 655-661 (c) European Geophysical Society 2002

\title{
The structure of mid- and high-latitude ionosphere during September 1999 storm event obtained from GPS observations
}

\author{
I. I. Shagimuratov ${ }^{1}$, L. W. Baran ${ }^{2}$, P. Wielgosz ${ }^{2}$, and G. A. Yakimova ${ }^{1}$ \\ ${ }^{1}$ WD IZMIRAN, Kaliningrad, Russia \\ ${ }^{2}$ Institute of Geodesy, University of Warmia and Mazury in Olsztyn, Poland \\ Received: 12 July 2001 - Revised: 18 January 2002 - Accepted: 29 January 2002
}

\begin{abstract}
TEC data, obtained from over 60 GPS stations, were used to study the ionospheric effects of the 12-16 September 1999 magnetic storm over Europe. The spatial and temporal changes of the ionosphere were analysed as a time series of TEC maps, which present 15 min averages of TEC. The data set consisting of GPS observations, collected by a dense network of European stations, with sampling rate of $30 \mathrm{~s}$, enable the creation of TEC maps with high spatial and temporal resolution. The storm included the positive as well as the negative phase. The positive phase took place during the first storm day of 12 September 1999. The short-lived daytime TEC enhancement was observed at all latitudes. The maximal enhancement reached a factor of 1.3-1.5. On the second and third days, the negative phase of the storm developed. The TEC decrease was registered regardless of time of the day. The TEC depression exceeded $70 \%$ relative to quiet days. On the following days (15 and 16 September), a significant daytime enhancement of TEC was observed once again. The complex occurrence of the ionospheric storm was probably related to the features of development of the magnetic storm. We found out that during the storm the large and medium-scale irregularities developed in the high-latitude ionosphere. The multi-stations technique, employed to create TEC maps, was particularly successful while studying the mid-latitude ionospheric trough. We found out that the essential changes of TEC during the storm, which were registered at the auroral and sub-auroral ionosphere, were connected with the effect of the trough and its dynamics, which depends on geomagnetic activity.
\end{abstract}

Key words. Ionosphere (ionospheric disturbances; auroral ionosphere; mid-latitude ionosphere)

\section{Introduction}

Nowadays, GPS measurements are commonly used to investigate the structure and dynamic of the ionosphere. Recently,

Correspondence to: L. W. Baran (baran@uwm.edu.pl) several authors used GPS networks to study TEC during a storm (Ho et al., 1998; Musman et al., 1998; Jakowski et al., 1999; Baran et al., 2001). Those studies, in general, concern the analyses of winter events during solar minimum. It was discovered that the significant positive effect was the main feature of the winter storms. It is known that the ionospheric effects of a storm essentially depend on a season (FullerRowel et al., 1996). Here, we present the analysis concerning the ionospheric response to the September 1999 storm. The paper describes in particular the response of TEC to the storm in the auroral and sub-auroral ionosphere of the $\mathrm{Eu}$ ropean sector. The comparison of storm-time behaviour of TEC with $f o \mathrm{~F} 2$ measurements at different latitudes is also presented. GPS observations of EPN (EUREF Permanent Network) stations were used to produce TEC maps over Europe. A dense network of GPS stations enabled one to study TEC over Europe with high spatial and temporal resolution and to find out dramatic TEC changes during the storm. We discuss the main reasons of these phenomena.

\section{Geomagnetic conditions}

September 1999 included a few magnetic active periods. We will discuss the intensive disturbances of 12-16 September. The variations of $K p$ and $D s t$ indexes are presented in Fig. 1. The sudden commencement of the storm occurred at 04:00 UT on 12 September. The maximum sum of $K p$ reached 39 on 13 September. The storm consisted of a series of intensive geomagnetic bays.

\section{Data source}

GPS measurements collected at EPN were used to obtain the TEC distribution over Europe during the storm. We included more than 60 GPS stations into the processing. A map of stations used in this study is presented in Fig. 2. 

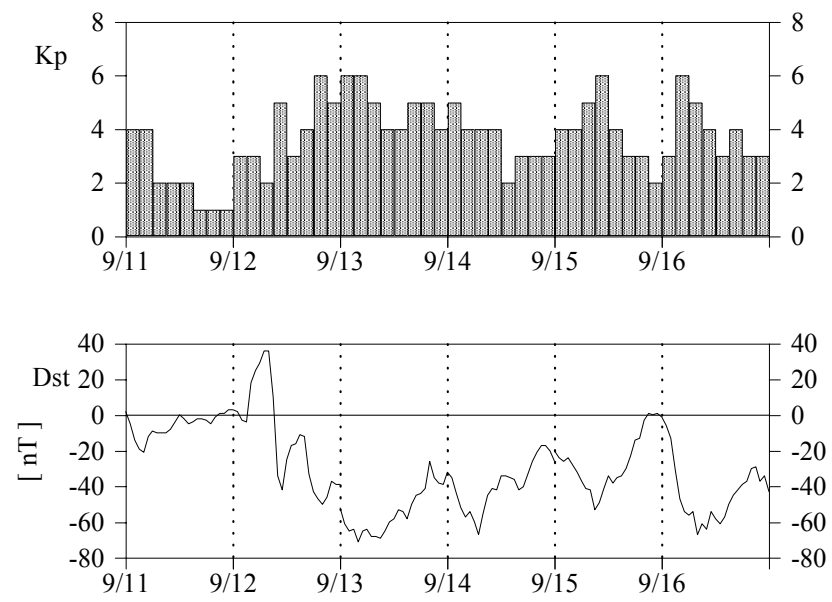

Fig. 1. $K p$ and Dst variations during 11-16 September 1999.

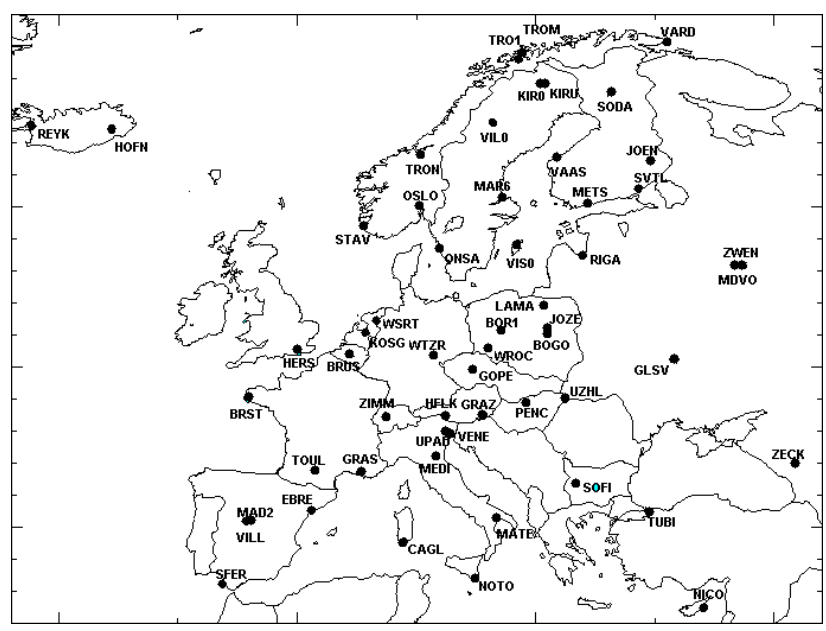

Fig. 2. Map of the EPN stations used in this paper.

\section{Estimation technique}

While estimating TEC from GPS observations the ionosphere was approximated by a spherical shell at a fixed height of $350 \mathrm{~km}$ above the Earth's surface. We used a simple geometric factor to convert slant TEC into a vertical one. High precision GPS phase measurements were used while processing. Phase ambiguities were removed by fitting phase measurements to the code data collected along the individual satellite pass. After the pre-processing phase, measurements contained an instrumental bias only. The absolute TEC and the instrumental bias were estimated using the single site algorithm (Baran et al., 1997). The biases were determined for every individual station using the GPS measurements and for all satellite passes over a site during a $24 \mathrm{~h}$ period. Diurnal variations of TEC over a site and the biases for all satellites were estimated simultaneously. We used this technique to process all observations from all stations, so instrumental biases were removed. Using this procedure we calculated an absolute line of sight TEC for all satellite-receiver paths.

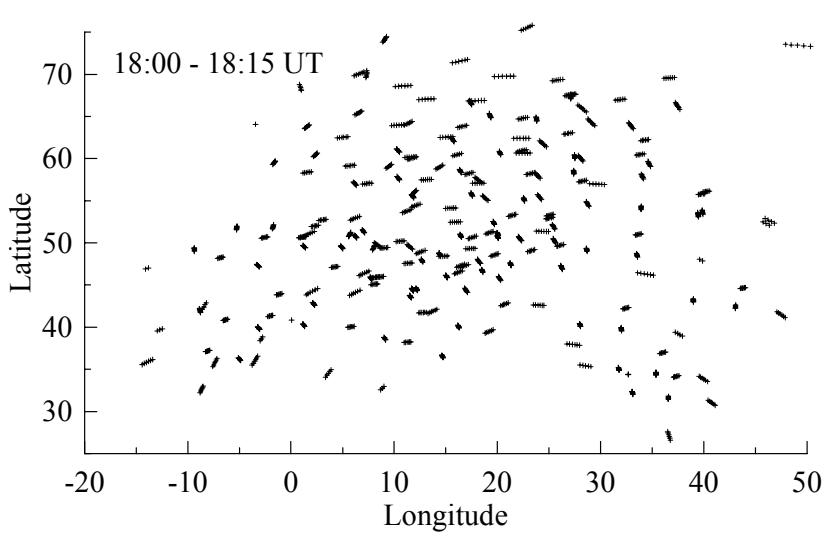

Fig. 3. The available TEC observations at $350 \mathrm{~km}$ altitude for a $15 \mathrm{~min}$ period.

The measurements were fitted to a surface harmonic expansion in $\Theta$ and $\Phi$, in order to obtain the spatial and temporal variations of TEC and to produce TEC maps. The chosen coordinate system is the geographic latitude $(\Theta)$ and longitude $(\Phi)$. Only GPS observations with elevation angles above $20^{\circ}$ were used in the calculations. TEC was modelled with a spherical harmonic expansion to degree 16 and order 16. Accuracy of TEC maps depends on the spatial gaps in the TEC data (Manucci et al., 1998). The large number of GPS stations in Europe provides good coverage for the observational data. Figure 3 shows the shell coverage for data arcs of $15 \mathrm{~min}$. The adequate shell coverage yielding a reasonable surface harmonic fit provides a spatial resolution of TEC 100-200 km with temporal resolution of $15 \mathrm{~min}$, with RMS about 0.5-2 TECU.

In order to clearly identify the ionospheric changes during the storm, we computed the percentage change of stormtime TEC relative to TEC for quiet conditions. To obtain the quiet time data, we averaged TEC from 5 magnetically quiet days. The maps over Europe, in this case, were produced every $15 \mathrm{~min}$. To discuss the storm behaviour in detail, various temporal and spatial TEC profiles were obtained from TEC maps. All TEC data were given in TEC units $\left(1 \mathrm{TECU}=10^{16}\right.$ $\left.\mathrm{el} / \mathrm{m}^{2}\right)$.

\section{Diurnal variations of TEC and $f o \mathrm{~F} 2$}

Ionospheric storm effects in TEC and in electron density of F2-region are illustrated in Fig. 4. We used data from four ionosonde stations, in the range of $42-68^{\circ} \mathrm{N}$ latitude in the European sector. In the first approximation, TEC can be expressed via the electron density in the peak of the F2 region (Nmax) and the ionospheric slab thickness $(\tau)$, which reflects the shape of the ionospheric height profile (Goodwin et al., 1995):

$T E C=N \max \cdot \tau=1.24 \cdot 10^{10}(f o \mathrm{~F} 2)^{2} \cdot \tau$, 

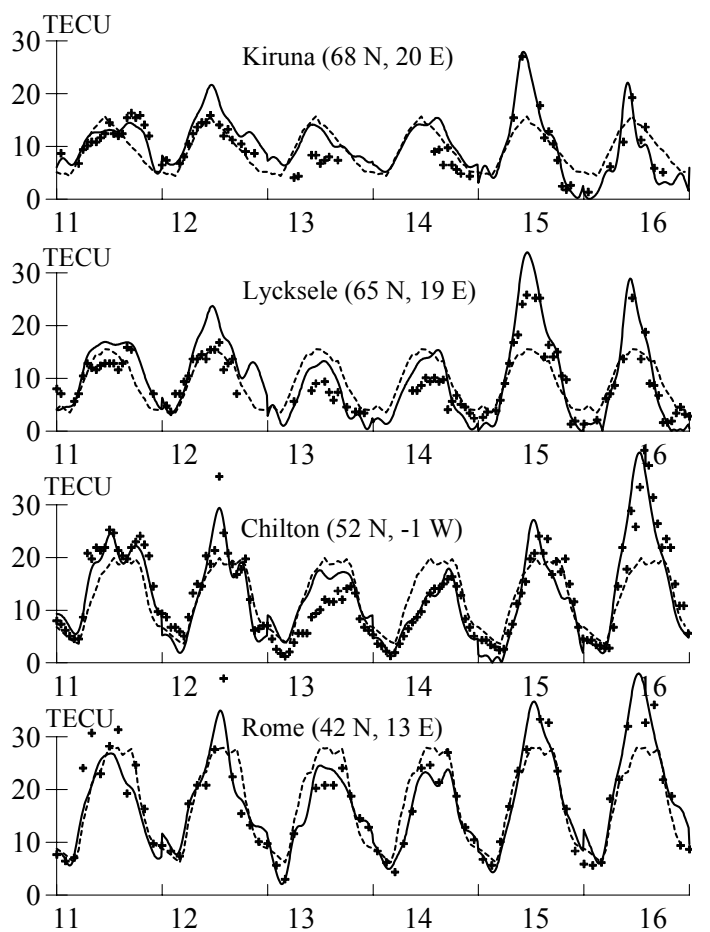

Fig. 4. Diurnal variation of TEC (solid curves), $(f o \mathrm{~F} 2)^{2}$ (crosses) and monthly median (dots) in relative scale during 11-16 September.

where $f o \mathrm{~F} 2$ is given in $\mathrm{MHz}$, TEC in $\mathrm{e} / \mathrm{m}^{2}$ and $\tau$ in meters. So, if the slab thickness is not changed there the TEC is in proportion to the square of $f o \mathrm{~F} 2$. In Fig. 4, the square of foF 2 was normalized to $1 / 3$.

On the first day, the positive effect in TEC and $f o \mathrm{~F} 2$ took place near noon at all stations. On the second and third days, the negative effects were recognized at all stations and were more pronounced at high-latitudes. On the whole, the good correlation between the total electron content and $\mathrm{NmF} 2$ took place for all stations during the storm. The diurnal behaviours of TEC and $(f o \mathrm{~F} 2)^{2}$ were similar. Synchronous behaviour of these parameters was violated on 13 and 14 September at auroral and sub-auroral stations. This gives evidence, that during the negative phase of the storm, the ionospheric shape parameter $-\tau$ was clearly changed.

The strong positive effect was observed in TEC and $f o \mathrm{~F} 2$ during the daytime on 15 and 16 September. At higher latitudes, this effect was more pronounced on 15 September, and at lower latitudes, it was more pronounced on 16 September. This series of TEC enhancements was probably related to the development of the magnetic storm, which includes the sequence of magnetic bays. The deep depression in ionisation after noon on 15 and 16 September 1999 may be related to the trough.
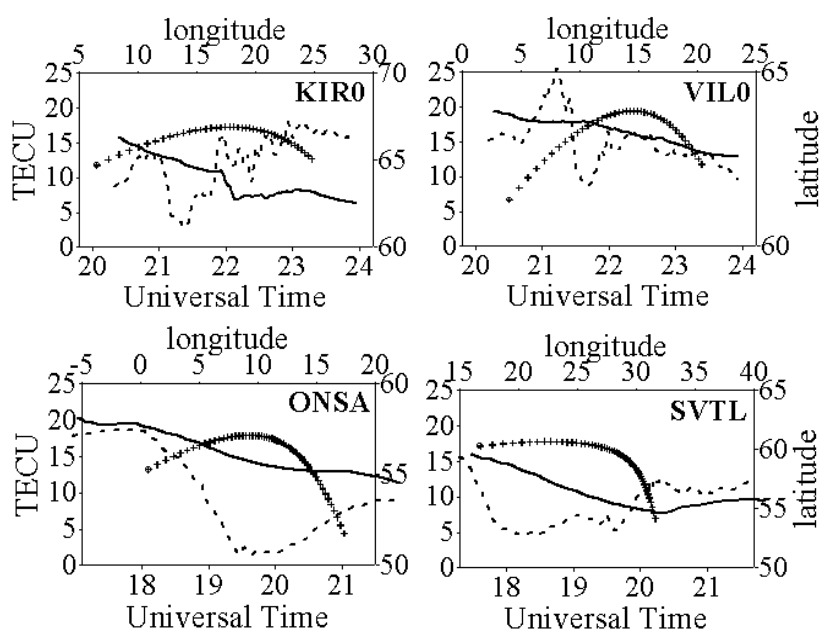

Fig. 5. Temporal TEC variations along individual satellite passes for PRN 30 (top panel) observed at PNSA $\left(57.4^{\circ} \mathrm{N}, 11.9^{\circ} \mathrm{E}\right)$ and SVTL $\left(60.5^{\circ} \mathrm{N}, 29.8^{\circ} \mathrm{E}\right.$ ), as well as for PRN 9 (bottom panel) observed at KIRO station $\left(67.9^{\circ} \mathrm{N}, 21.1^{\circ} \mathrm{E}\right)$ and VIL0 station $\left(64.7^{\circ} \mathrm{N}, 16.6^{\circ} \mathrm{E}\right)$ on 11 September (solid curves) and 12 September (dots). Crosses show location of satellite traces at ionospheric height in geographic coordinates.

\section{Spatial variations of TEC during the storm}

Fine spatial structure of the ionosphere was well traced in the phase data for individual satellite passes. Figure 5 demonstrates the variations of TEC along the satellites' traces on the quiet day of 11 September $\left(\sum K p=16\right)$ and the disturbed day of 12 September $\left(\sum K p=31\right)$ for satellites PRN 9 and 30 , which were simultaneously observed at spaced stations. Since GPS satellites are in 12-sideral-hour orbits, the constellation repeats for consecutive days, expect for the fact that a satellite arrived $4 \mathrm{~min}$ earlier each day. In Fig. 5, one can see that during the storm, the auroral and sub-auroral ionosphere were essentially modified. The large- and mediumscale structures with deep TEC changes developed after noon during the storm. TEC behaviour at spaced stations was also different. We attribute the large-scale ionospheric structure to the occurrence of the main ionospheric trough, which was moving towards the equator during the storm. In reality, the trough-like structure was observed at mid-latitude station Onsala (Fig. 5). The strong depression, when TEC values amounted to only a few TECU, was observed at latitudes below $57^{\circ} \mathrm{N}$.

\section{Storm-time TEC distributions over Europe}

Temporal evaluation of TEC distribution over Europe on the first disturbed day (12 September) is presented in Fig. 6 via the series of TEC maps. When producing the maps we used $15 \mathrm{~min}$ averages of TEC data. This approach provides detailed analysis of the ionospheric response to the storm. A significant feature in latitudinal variations of the ionosphere was the presence of the trough. In Fig. 6, one can see that 

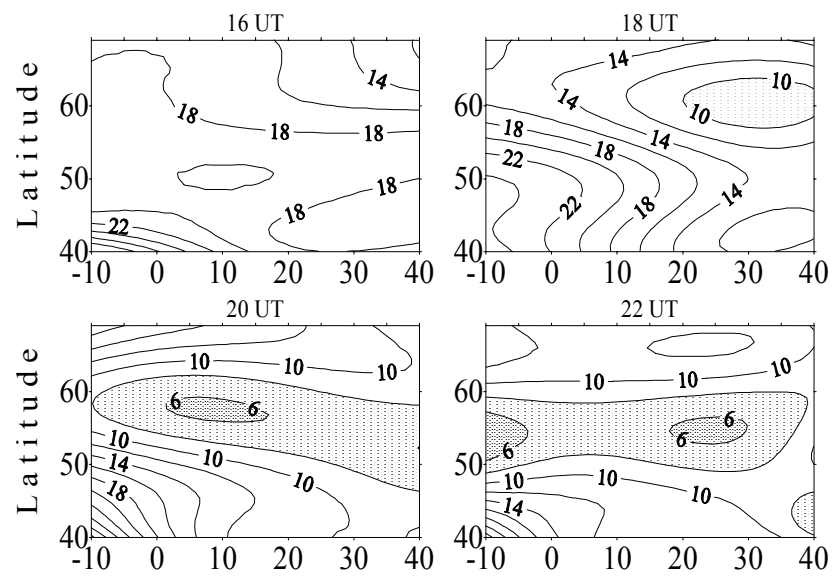

Longitude

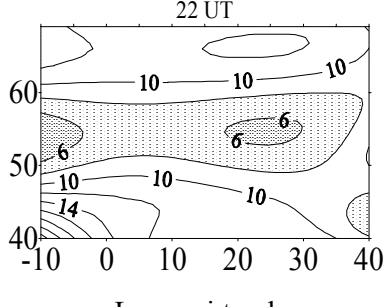

Longitude

Fig. 6. TEC maps over Europe (geographic coordinates) for afternoon sector of 12 September.

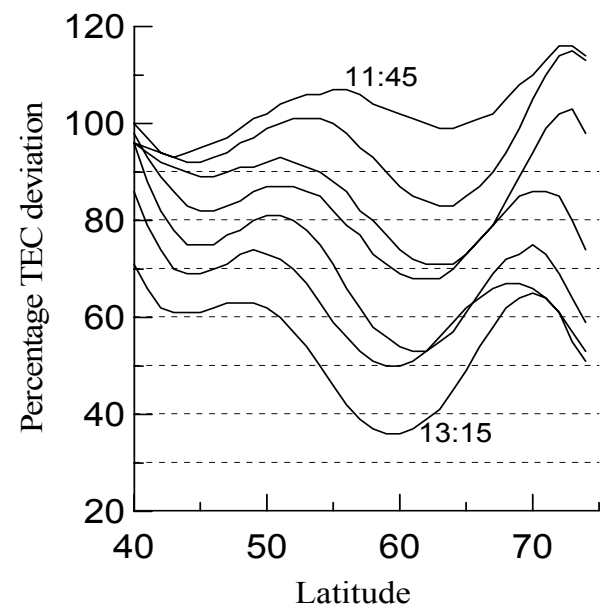

Fig. 7. The $15 \mathrm{~min}$ latitude profiles of TEC ratios with respect to the quiet time for period of 11:45-13:15 UT, 12 September 1999. Each curve is shifted downwards by 20 TECU.

the trough first occurred east and after that was heading due west.

In comparison with quiet geomagnetic conditions the daytime ionisation was enhanced at high-latitudes and next, it moved towards low-latitudes. The enhancement of TEC made up $30-50 \%$ at high latitudes, and $60-80 \%$ towards the equator. The positive effect in TEC lasted until 15:0016:00 UT and next, the negative phase of the storm started.

In Fig. 4, around noon on 12 September, one can see a marked surge in diurnal variations of TEC and $f o \mathrm{~F} 2$. In monthly averages, as well as during quiet days, the surge was not detected. The analysis of diurnal variations of TEC at different latitudes showed that the surge moved towards the equator. The surge at the lower latitudes appeared about $2-3 \mathrm{~h}$ later. The delay corresponded with the velocity of the perturbation propagation, about $200-400 \mathrm{~ms}^{-1}$.

TEC maps with 15 min intervals enabled one to obtain
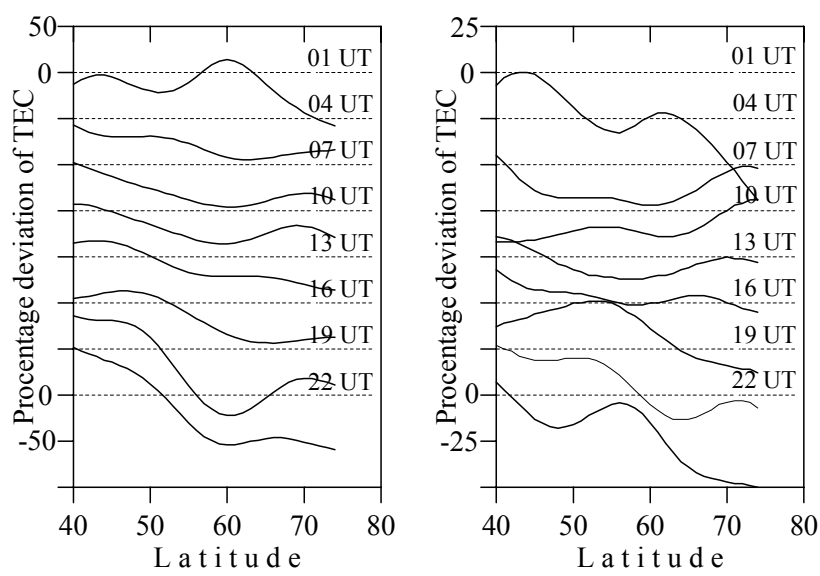

Fig. 8. Latitude profiles of TEC changes relative to the quiet time for 13 September (left panel) and 14 September (right panel) at different hours. Each curve is shifted downwards by $50 \%$ in left panel and by $25 \%$ in the right one.
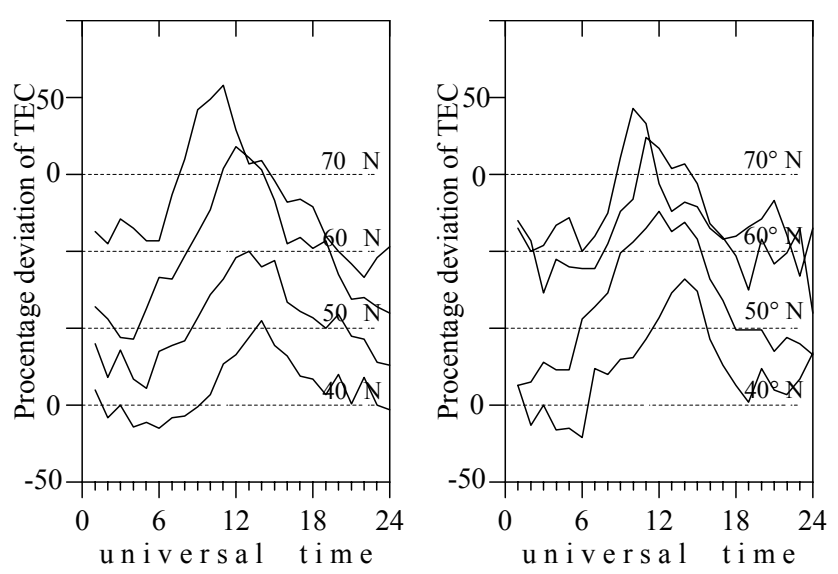

Fig. 9. Diurnal profiles of relative TEC changes on 15 September (left panel) and 16 September (right) at different latitudes $\left(40^{\circ}, 50^{\circ}\right.$, $\left.60^{\circ}, 70^{\circ} \mathrm{N}\right)$. Each curve is shifted downwards by $50 \%$.

a detailed picture of the TEC perturbation related to this surge. Figure 7 demonstrates the temporal evaluation of latitudinal profiles of TEC deviation. Here, one can see the large-scale wave-like perturbation moving towards the equator. It is interesting to note that the amplitude of the perturbations increased with time. The Time delay of the wave surge corresponds to a propagation velocity of the perturbation, about $200 \mathrm{~m} \mathrm{~s}^{-1}$. This velocity is slower than the propagation of perturbation of the winter storm of 10 January 1997 (Jakowski et al., 1999).

During 13 and 14 September, the negative phase of the storm in TEC distribution over Europe took place. Latitude profiles of TEC on 13 and 14 September relative to averaged quiet values over longitude $20^{\circ} \mathrm{E}$ are presented in Fig. 8 . The daytime depressions exceed $50 \%$ on 13 September and $30 \%$ on 14 September. The strong latitudinal variations of relative TEC deviation in the evening/night sector is very interesting. We attribute this effect to the occurrence of the difference in 

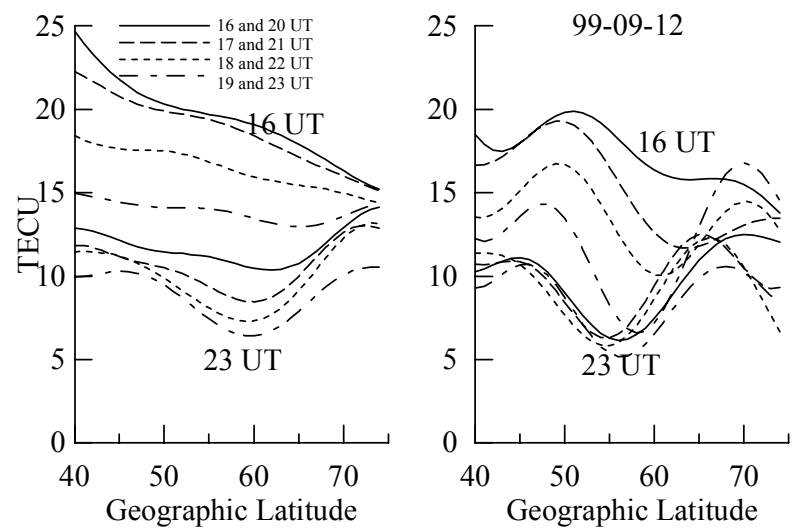

Fig. 10. The dynamics of latitude profiles at post-noon sector for quiet day (11 September - left panel) and disturbed days. location of the trough for disturbed and quiet geomagnetic conditions. On 13 September, negative effects were more pronounced at latitudes over $30-55^{\circ} \mathrm{N}$. At same time, on 14 September, the TEC depression was observed at all latitudes under consideration. It is interesting to note the longitudinal dependence in development of the storm at mid-latitude on 13 September. At longitudes over $20^{\circ} \mathrm{E}$, the positive effect was detected, and at longitudes under $20^{\circ} \mathrm{E}$, the negative effect occurred. Such a picture of TEC behaviour gives evidence of the regional feature in development of the storm (Cander and Mihajlovic, 1998).

The feature of the storm is the occurrence of the daytime positive effect on a recovery stage of the storm on 15 and 16 September (Fig. 9). The effect is observed in TEC, as well as in $f o \mathrm{~F} 2$ data (Fig. 4). Attention should be paid to the temporal shift in maximum percentage deviation when moving from high- to low-latitudes. The maximum at the lower latitudes appeared about 2-3 h later. At high-latitudes, the duration of the positive effect was about 3-4h. After 12:00 UT, at $70^{\circ}$ latitude, the negative effect took place on 15 and 16 September. One should note that the maximal TEC enhancement occurred at latitudes about $60^{\circ} \mathrm{N}$ on 15 September, and at lower latitudes during 16 September. At all latitudes, the positive effect was observed only during daytime. At night, at high-latitudes, the negative effect usually took place on 15 and 16 September.

\section{Storm-time dynamics of the ionospheric trough}

Temporal TEC variations for individual satellite passes presented in Fig. 5 and also TEC maps in Fig. 6 demonstrate the trough-like structures in TEC behaviour. The occurrence of the trough at latitudinal TEC profiles is presented in Fig. 10 for quiet and disturbed days. For quiet geomagnetic conditions the trough-like structure was observed after 19:00 UT. The TEC at the polar wall and at the bottom of the trough was in the ratio of 2 to 1 . The equator-side wall was weakly pronounced. On a disturbed day (12 September), the trough occurred after 15:00 UT (16:30 LT), with the depth of the trough increasing. Both walls of the trough were particularly pronounced.

We attribute the TEC enhancements at the polar-side of the trough on 12 September to the effect of the auroral precipitations. The analyses of GPS data showed that during the storm the intensity of GPS signal phase fluctuations increased. As it was shown by Aarons et al. (2000), the phase fluctuation development during the storm is well correlated with ultraviolet image (UVI) intensity obtained from the Polar satellite. The increase in UVI intensity is evidenced by the precipitation in E- and/or F-regions of the ionosphere.

On 13 September, the equator-side wall was well pronounced, and the polar-side wall was weak. TEC at the equator-side wall was 3-4 times higher than at the bottom of the trough. TEC at the bottom of the trough amounted to only 3 TECU. The equatorward displacement of the trough was clearly seen during the disturbances. Location of the trough was also moved to the equator. On the whole, the trough underwent a substantial change during the disturbance.

\section{Discussion and conclusions}

The September 1999 storm consisted of a short-duration positive effect on the first day on a driven stage of the storm and a long-lasting negative phase on 13 and 14 September. This is a well-known picture in the development of the ionospheric storm. At the same time the storm had a number of features.

The positive effect was characteristic for a winter storm (Fuller-Rowell et al., 1996). As an example, the TEC enhancement on the 22 November 1997 storm (Baran et al., 2001) and the one on 10 January 1997 (Ho et al., 1998) exceed $100 \%$. But for the September storm under consideration, the daytime TEC increased only by $20-30 \%$. The maximum of TEC enhancement occurred during the subminimum of the $D s t$ index $(-40 \mathrm{nT})$. For the winter storm of 10 January 1997, TEC maximum coincided with the minimum of the $D s t$ index $(-80 \mathrm{nT})$. Both storms started nearly at the same time. A difference in the occurrence of the positive effect can be related to a seasonal effect, and naturally, also with an intensity of a storm. 
The feature of the September storm is strong daytime TEC enhancements, which were observed on the following days of 15 and 16 September, at the recovery stage of the storm. The TEC enhancements reached up to $80 \%$ relative to quiet conditions. The maximal enhancements also coincided with a sub-minimum in the Dst index of $-67 \mathrm{nT}$ and $-53 \mathrm{nT}$ on 15 and 16 September, respectively. It is interesting to note that the enhancement took place only during the daytime and a $2-3 \mathrm{~h}$ duration of the positive effect was observed at highlatitudes. At low-latitudes, the positive effect lasted during the entire daytime.

Using 15 min TEC maps we found a wave-like perturbance with latitudinal scale of about $1500-2000 \mathrm{~km}$, which showed expansion of the daytime TEC enhancement towards the equator (Fig. 7). The equatorward propagation of a peak in percentage deviation of TEC relative to a quiet time is recognized markedly on 15 and 16 September (Fig. 9). A propagation velocity of the perturbance made up about $200 \mathrm{~ms}^{-1}$. It was essentially slower than during the winter storm of 10 January 1997, which was estimated at 400 $900 \mathrm{~ms}^{-1}$ (Jakowski et al., 1999). The positive effect may be explained by the disturbances of meridian neutral wind, which causes the lifting of ionospheric plasma along geomagnetic field lines to areas with lower ion-loss rates. The thermospheric neutral wind disturbance is related to stormtime auroral energy input, resulting in both the passage of travelling atmospheric disturbances (TADs) excited during the storm onset, as well as the disturbed global wind circulation (Forster et al., 1999).

The negative effect during the daytime on 13 and 14 September was pronounced in both TEC and F0F2 data (Fig. 4). The daytime depression on 13 September was observed at latitudes over $50^{\circ} \mathrm{N}$ and reached $50 \%$. The striking feature of the storm was the regional effect in the ionospheric response during the negative event on 13 September, which was observed at latitudes under $50^{\circ} \mathrm{N}$. The positive effect was first detected east and the negative one, west of Europe (Fig. 11). Observed regional structures were maintained during a long period from 10:00 UT until 20:00 UT. The negative effect may be attributed to thermosphere circulation, composition changes, and a decrease in $[\mathrm{O}] /\left[\mathrm{N}_{2}\right]$ after the stormdriven phase, resulting in the ion-loss rate enhancement withering in the composition disturbance zone (Fuller-Rowell et al., 1994)

The strong storm effect in TEC took place at auroral and sub-auroral latitudes in the afternoon and night hours, when strong TEC depressions exceeded $100 \%$ relative to quiescent conditions. We attribute this effect to the occurrence of the ionospheric trough, which, during the storm, moved towards lower latitudes. We found that the trough was regularly observed in TEC. A lower latitudinal location of the trough relative to this, obtained from ionosonde and DE2 satellite data (Werner and Prolss, 1997), is worth noting. The lower location of the trough was recognized in TEC maps, as well as in TEC variation for individual satellite passes (Fig. 5). The lower location of the trough can be related to an integral effect in height structure of the ionospheric trough. In addition, the effect can be caused partly by using the one-layer approximation ionosphere when reconstructing absolute TEC from GPS observation. The two-layer approximation (Juan, 1997) can more exactly represent TEC distribution.

Acknowledgements. The authors are grateful to the IGS community and WDC-C1 for GPS and ionosonde data. We would like to thank A. Namgaladze for useful discussion and also Luiza Koltunenko for her help in GPS data processing.

Topical Editor M. Lester thanks C. Mitchell and E. Essex for their help in evaluating this paper.

\section{References}

Aarons, J., Lin, B., Mendillo, M., Liou, K., and Codrescu, M.: Global Positioning System phase fluctuations and ultraviolet images from the Polar satellite, J. Geophys. Res., 105, A3, 52015213, 2000.

Baran, L. W., Shagimuratov, I. I., and Tepenitzina, N. J:, The use of GPS for ionospheric studies, Artifical Satellites, 32, 49-60, 1997.

Baran, L. W., Ephishov, I. I., and Shagimuratov, I. I.: Ionospheric Total Electron Content Behaviour During November 1997 Storm, Phys. Chem. Earth (C), 26, 341-346, 2001.

Cander, L. R. and Mihajlovic, S. J.: Forecasting ionospheric structure during the great geomagnetic storm, J. Geophys. Res., 103, A1, 391-398, 1998.

Forster, M, Namgaladze, A. A., and Yurik, R. Y.: Thermospheric composition changes deduced from geomagnetic storm modeling, Geophysical Research Letters, 26, 16, 2625-2628, 1999.

Fuller-Rowell, T. J., Codrescu, M. V., Moffett, R. J.: and Quegan Response of the thermosphere and ionosphere to geomagnetic storms, J. Geophys. Res., 90, 4229-4248, 1994.

Fuller-Rowell, T. J., Codrescu, M. V., Rishbeth, H., Moffett, R. J., and Quegan, S.: On the seasonal response of the thermosphere and ionosphere to geomagnetic storms, J. Geophys. Res., 101, 2343-2353, 1996.

Goodwin, G. L., Silby, J. H., Lynn, K. J., Lynn, W., Breed, A. M., and Essex, E. A.: GPS satellite measurements: ionospheric slab thickness and total electron content, J. Atmos. Terr. Physics, 57, 1723-1732, 1995.

Ho, C. M., Manucci, A. J., Linqwister et al.: Global ionospheric TEC variations during 10 January 1997 storm, Geophys. Res. Letters, 25, 2589-2592, 1998.

Jakowski, N., Schluterm, S., and Sardon, E.: Total electron content of the ionosphere during the geomagnetic storm on 10 January 1997, J. Atmos. Terr. Physics, 61, 299-307, 1999.

Juan, J. M.: A two-layer model of the ionosphere using GPS data, Geophys. Res. Letters, 24, 393-396, 1997.

Mannucci, A. J., Wilson, B. D., Juan, D. N., Ho, C. H., Lindqwister, U. J., and Runge, T. S.: A global mapping technique for GPSderived ionospheric TEC measurements, Radio Science, 33, 3, 565-582, 1998.

Musman, S., Mader, C., and Dufton, C. E.: Total electron content changes in the ionosphere during the 10 January 1997 disturbances, Geophys. Res. Letters, 25, 3055-3058, 1988.

Werner, S. and Prolss, G. W.: The position of the ionospheric trough as a function of local time and magnetic activity, Adv. Space. Res., 20, 9, 1717-1722, 1997. 